\title{
The Use of Lace and Passementerie in China in the Qing Dynasty
}

\author{
Huicui Miao ${ }^{1} \&$ Feng Zhao ${ }^{1,2}$ \\ ${ }^{1}$ School of Fashion and Art Design, Donghua University, Shanghai, China \\ ${ }^{2}$ China National Silk Museum, Hangzhou, China \\ Correspondence: Feng Zhao, China National Silk Museum, Hangzhou, China. Tel: 86-139-5806-6182. E-mail: \\ 1007043621@qq.com
}

Received: September 27, 2021

Accepted: October 24, 2021

Online Published: November 29, 2021

doi:10.5539/ass.v17n12p26

URL: https://doi.org/10.5539/ass.v17n12p26

\begin{abstract}
With the increasing normalization of social exchanges between China and the west in the late Qing Dynasty, a large number of Western skills and products brought by missionaries were introduced into China, including a large number of lace and passemeterie. The description and analysis of such trimmings are not sufficient now. This paper takes the court dress at that time as the physical reference, analyzes it according to historical documents and western techniques. It shows that the earlier lace used is metal lace; During the Guangxu period, a large number of net lace appeared; At the same time, passemeterie was also widely used in China. Chinese society has no clear conceptual difference between lace and passemeterie, and they both are used as an edge decoration product from other culture.
\end{abstract}

Keywords: lace, passemeterie, Qing Dynasty

\section{Preface}

Lace is an important category in European clothing. It occupies an important position in the clothing of the Renaissance and later. In the long process of development, the types of lace are constantly innovating and changing. But for China, an ancient country in the east, lace decoration is undoubtedly an exotic product. The general public's understanding of it is a decorative accessory in Western-style clothing, especially dresses and skirts since modern times.

However, looking through the history of modern costumes, we can find that as early as the Qing Dynasty, the western lace decorative art has appeared in the palace and folk costumes, and in the Republic of China, it also shined in the qipao, the most common costume at that time. However, because it is somewhat similar to the original Chinese clothing accessories, it has not been analyzed as a unique decorative category in the West.

This article attempts to find the introduction and use of lace and other fringe decorative arts in the Qing Dynasty. Through the excavation of relevant early documents and the Qing Dynasty court costumes preserved in the museum, we can find out the types of western fringe decorations used at that time and their artistic origins in European culture. Explore the differences between Chinese and Western cultures and markets, and conduct corresponding analysis and research on the special usage habits formed in China.

\section{Documents of the Use of Lace and Passementerie}

The earliest record of western lace and passementerie appears in a list (《宫中进单》) in the 33rd year of Qianlong(1768), in which lace is described as "golden lace". However, after these lace were offered to Qianlong as a tribute, they were rejected by Qianlong together with part of the tribute. It should be noted that this selective refusal is a common practice for offering tribute, and it does not mean that the court does not like such objects.

The time when Western lace and passementerie become an important decoration on Chinese costumes, should be datesd at the Jiaqing period. This kind of lace was described in one book (《夷患备尝记》) written by Cao Sheng in 1842 in the Qing Dynasty. He wrote in the book: Guizi langan (鬼子栏干) was foreign products and named by its origen. It entered China During the Jiajing period, people love it because of the rareness, and decorated them on clothes. Later, the ghost (guizi) characters are not lucky enought to be writen in the marriage ceremony gift list, it was called as saw, which is similar in shape. Later, it is called Guizi (“桂子, 贵子” which are words with the same pronunciation but different meanings). The strange patterns and different colors were renovated everyday. The inland people can also do it buy themselves. This is the most comprehensive description of lace in 
early Chinese records. It can be seen from this paragraph that "guizi langan" is a category imported from the West. "gui" means ghost in Chinese, "guizi" is a derogatory term for foreigners in the Chinese society at that time. "langan"means railing in Chinese,At that time, people also used this word to refer to edge decoration, regardless of whether the decoration was domestic or foreign. When facing the edge decoration of foreign style, people use these two words together. Because of its special decorative effect and the promotion of the social pursuit of foreign goods at that time, it was sought after by the Chinese people, and even used as a gift in a marriage gift list. It can be seen that this product has already been widely used in civilian society at that time.

Painting Ferry Talk(《画舫余谈》), written in the twenty-third year of Jiaqing (1818), also mentioned that such products were sold in Nanjing as one of the most commonly used goods by women at the time. In the 20th year of Daoguang (1840), the governor of Jiangsu, Yu Qian, also mentioned the extravagant use of "guizi langan". It can be seen that this kind of product has always been a popular decoration from Jiaqing to Daoguang .

A poem in the Guangxu period (1875-1909) wroted: the "guizi langan" was all over the body. It describes the grand occasion of multiple border decorations in women's clothing in Beijing at that time, and it can be seen that "guizi langan" occupied the main position of women' s fashionable dress at the time.

The use of lace in China during this period can also be proved in foreign records. In 1897, Acting Consul Tratman writes from Chungking: The fashion of trimming native female costume with lace, which is so prevalent in Shanghai, has not yet shown itself to any great extent in these far-off regions, but signs are not wanting that a change in this respect may be looked for. At the same time, the Dutch consul in Yichang also mentioned lace and socks, saying that the former (namely lace) was often used by Chinese women at that time, and this newer fashion can be traced back two or three years ago.As early as 1881, there were advertisements for the sale of western lace in a newspaper in China. In 1934, the economic news still recorded that the imports of clothing trims used by fashionable women in China increased significantly that year compared with last year.

\section{Variety of Lace Passementerie Used in China}

\subsection{Metal Lace}

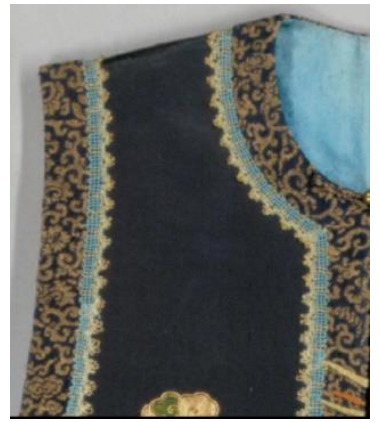

Figure 1. Large waistcoat with embroidery

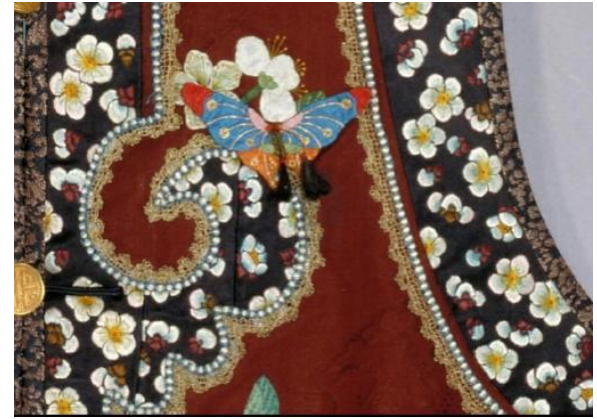

Figure 2. Lady's waistcoat waistcoat with flower and butterfly patterns

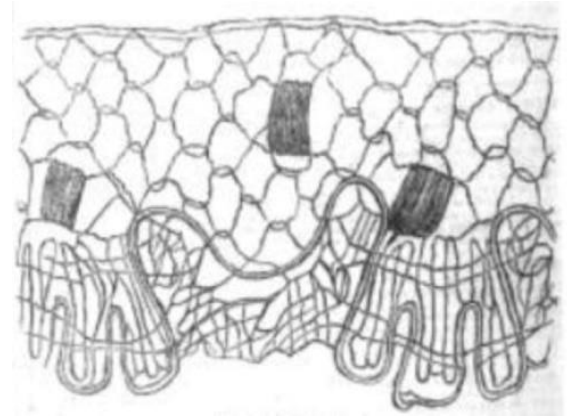

Figure 3. Illustration of Chinese lace

Metal lace was the earliest lace type we can see in the the court costumes in the Qing Dynasty. One is a large waistcoat with a satin embroidered crane pattern in the Daoguang period (1821-1851) (Fig 1), the other one is a lady's waistcoat waistcoat with flower and butterfly patterns in the Tongzhi period (1862-1875) (Fig 2). They both use the metallic lace as edge decoration. There are few costumes with western lace in the early Qing Dynasty, they are the two of them.

As mentioned earlier, one of the characteristics of this kind of foreign borders is the jagged edge, that is why it was called saw. Carefully observe the innermost edge decorations on the two pieces of clothing. They show obvious jagged edges, which are rarely seen in traditional Chinese braid decorations. This artistic expression is very similar to the simple straight lace made in Europe. In addition, the two edge decorations have metallic luster, and the material used for one of the pure gold laces can be determined to be gold thread. This also coincides with the description in the Chinese records, because in some records, the word "gold" is often used to describe "guizi langan". The simple lace structure and metal material characteristics show that this type of lace is metal lace which is common in Europe.

It also mentioned that the Chinese also tried to make this kind of product not long after this product was imported into China. This view can also be confirmed by records in British newspapers. In 1844, British 
newspapers reported that a British soldier saw this kind of lace made by a local woman near Nanjing area(Fig 3). As a lace worker, he was very interested in it and brought back a part of it. It can be seen from the photo that this kind of lace is very similar to the metal lace.

\subsection{Net Lace}

As mentioned above, the use of "Guizi Langan" was also mentioned in the poems of the Guangxu period (1875-1909). Although the terms used here are not much different from the previous ones. But the type of lace in this period is different from the previous ones.

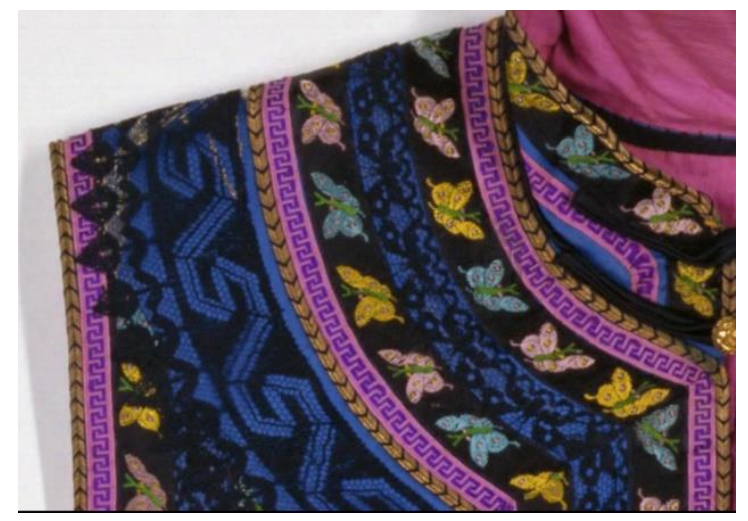

Figure 4. Small waistcoat

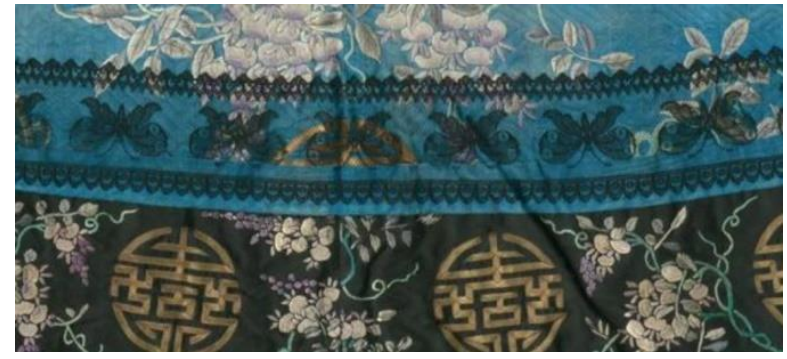

Figure 5. Light blue shirt of Cixi

In the report of the Chongqing consulate in 1897, it was mentioned that Almost all the lace imported is made of silk, a small quantity coming in being of cotton. About three-fourths of the total import is black in colour. In the same report, the Dutch consul in Yichang Said "The favourite style of lace is black, about one to two inches in width." The Dutch consul also specially reminded that the color of lace is very important in China. "After black, which is a long way first in favour, violet, and perhaps some shades of grey, would be saleable." But regarding the material of lace, the Dutch consul believed that "the lace used is all cotton lace, silk being beyond the means of all except the few very rich natives, and it is doubtful if even they would buy silk." From the description of the text, the lace mentioned here is far from the metal lace mentioned in the previous chapter. At this time, the lace is mainly black, and the material made has changed from metal to silk or cotton. It can be seen that in the Guangxu period, although the same Chinese name was still used, the type of lace referred to has changed. A large number of real objects that fit the description in this paragraph can be found, especially in the costumes of the Qing Dynasty during the Guangxu period and later, and they are basically net lace.

A small waistcoat in the Guangxu period (Fig 4) in the Palace Museum shows the extensive use of lace in the poem. A large number of complicated laces extend from the edges to the body, and the original fabric of the body is almost covered. This is a typical decorative method for women's clothing in the late Qing Dynasty. The black lace mentioned in foreign records also appeared on this garment. The lace shows a butterfly pattern on the net. There is also a butterfly pattern lace on a light blue shirt of Cixi period (Fig 5), but it has two more serrated edges than the former, and the patterns and nets are more delicate. The other black lace on the waistcoat are with geometric patterns and a continuous arrangement of flower branches with leaves on the net. This kind of lace also appears in the collections of the Shenyang Palace Museum and the collections of the Chinese History Museum. The patterns used are basically geometric patterns or flower patterns, with jagged edges on one or both sides. Only one yarn robe has a special blue lace pattern, orchid and crane, which has a strong Chinese taste.

According to observations, the lace in this kind of real object is likely to be a hand-made net lace imitation 
produced by a machine. Chantilly lace is the most representative one. Chantilly was a lace production center in France in the early 19th century, where blond lace was produced in large quantities. The products in the Chantilly area are gradually called Chantilly lace because of the good quality. Due to changes in fashion tastes in the 1840s, this type of lace began to use dark black silk threads in large quantities, also known as Black Lace. This black lace was one of the favorite laces of French families at the time. Later, due to the influence of the Second Empire, it faded for a while until it became popular again in the 1890s. The popular time of this lace is very close to the use period of this kind of lace in China. Therefore, the lace in this section can basically be considered to belong to this category.

However, most of these laces are not handmade, but machine products. As early as 1907, it has been mentioned in the book that Chantilly lace and other types of lace in the British market have lost their former glory, because these types of lace machines have been able to accurately imitate a large number of them. This is already the case in the UK market, not to mention that China's imports of such lace.

\subsection{Passementerie}

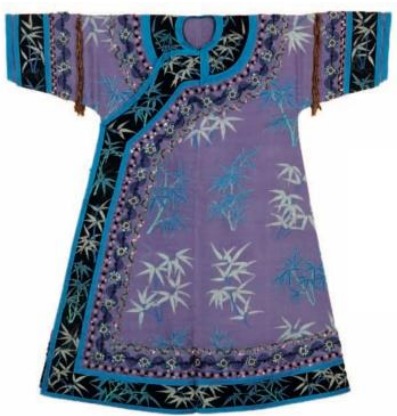

Figure 6. Snow green shirt

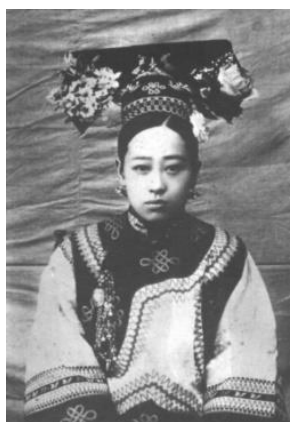

Figure 7. Manchu women

In addition to the previous two types of lace, the clothing of the late Qing Dynasty also used a large number of passementeries. This type of product has appeared in the Guangxu period. In Figure 6, the snow green shirt in the Guangxu period is decorated with many trims from the outside to the inside. the three innermost trims are all this kind of products. Compared with traditional lace products, this production is simpler to make, so it does not as delicate as lace. However, these products have more choices in materials and colors, and the decorative effects are colorful and eye-catching. Moreover, this kind of products can be made by machines, and they are more compact in price, so they can be used in a wide range. It not only appeared in large numbers in the court of the Qing Dynasty, but there were also many consumers In the civilian class. Manchu women like the one in Figure 7 is one is one of the examples. This type of product can be seen in a large number of images from the end of the Qing Dynasty and the beginning of the Republic of China. Even in the 20th century, when qipao was widely worn, it still appeared in large numbers on the skirts and collar edges of qipao, as a common matching element. So in the foreign imports at that time, the share of passementerie was much larger than that of lace.

Because the passementerie is widely welcomed. By 1920, Chinese companies had also joined the ranks of the production of such products. At that time, the Zhonghua Industrial Company published an advertisement in a newspaper, passementerie as the main products, was called as double-sided edges, lens trim, bead edge, skirt edge and so on.

\section{Conclusion}

As early as the Qianlong period, lace had appeared in court records, but it was not until the Jiaqing period that the border ornaments represented by lace were widely used in important cities in China, and gradually became an indispensable part of the hem decoration boom in the late Qing Dynasty. With the passage of time, the types of Western borders used in the palace changed from straight lace such as the original metal lace to net lace. Only a few of the net laces were pure handmade laces, and most of them were machine imitations. Later, the passementerie, which can imitate the decorative effect of lace edges, was widely used in the clothing of the late Qing Dynasty and the early Republic of China. Because of its better decorative properties and lower cost passementerie shared most market of lace. These types of products were originally imported into China from abroad, born out of traditional European fringe decorative arts. After entering China, it opened up a huge consumer market in the local area because of the fresh style, and promoted its local production in China. Until 1934, after the Qing government had collapsed, China still had reports of huge consumption of imported lace 
into the country from time to time. It can be seen that although China has been able to produce such products, people still respect them as foreign objects, resulting in continuous and large import demand.

Looking back at this period of history, we can also find that Western lace was the first to enter the Chinese market and played a certain role in guiding the public's decorating habits. However, when lace gradually promoted the edge decoration of Chinese clothing, it was divided up by the cheaper passementerie. In the aesthetics of the Chinese people, lace and passementerie have always been used as one product. However, in Western culture, although these two products are of the same origin, there has been a huge technological and artistic gap. There are two main reasons why Chinese society confuses these two types of products. First of all, there is no lace aesthetic tradition in the local culture. The once gorgeous and exquisite lace products have not appeared in Chinese society, so they cannot resonate the aesthetics of high-quality lace in China. Secondly, the introduction of lace into China was relatively late. At that time, the local lace art in Europe had gradually declined due to the impact of industrial machinery. After being introduced to China, lace has always been used as edge decoration. This form is basically similar to passementerie. Therefore, for Chinese without relevant knowledge, they are basically similar in artistic expression and use.

Therefore, when more decorative and cheaper products appear, Western women may struggle with machine lace and passementerie because they are full of memory for the nobility and elegance represented by handmade lace in the past. But Chinese consumers will not, the lack of memory of the handmade lace made them more comfortable and quick to accept the high-quality and inexpensive machine lace and passementerie.

\section{References}

Cao, S. (1989). Yi huan bei chang ji. Shanghai: Shanghai Ancient Books Publishing House.

Dong, J. (2009). Missionary tribute and the Qianlong emperor's western taste. The Qing History Journal, (3), 95-106. http://CNKI:SUN:QSYJ.0.2009-03-010

Mincoff, E., \& Marriage, M. S. (1907). Pillow Lace: A practical hand book. New York: E. P. Dutton and Company.

Palliser, F. B. (1902). A history of lace. London: Sampson Low.

Peng, Y. M. (2017). Paris fashion: A study of the history of modern French apparel. Shenyang, Liaoning: People's Publishing House.

Summary of archives of the office of interior affairs of the Qing Palace. (2005). Beijing: People's Publishing House.

Toomer, H. (2001). Antique Lace: Identifying types and techniques. Atglen: Schiffer Pub Ltd.

Yin, A. (2010). The shirts of the imperial concubines of the Qing dynasty. Forbidden City, (2), 64-73. http://CNKI:SUN:ZIJC.0.2010-02-022

Zhang, Z. (2021). Analysis on the art of edge decoration of women's casual wear in Qing palace- case study of collection in Shenyang Palace Museum. Journal of Zhejiang Fashion Institute of Technology, (6), 51-55, 96.

\section{Copyrights}

Copyright for this article is retained by the author(s), with first publication rights granted to the journal.

This is an open-access article distributed under the terms and conditions of the Creative Commons Attribution license (http://creativecommons.org/licenses/by/4.0/). 